$16^{\text {th }}$ International Congress of Metrology, 02001 (2013)

DOI: $10.1051 /$ metrology/201302001

(c) Owned by the authors, published by EDP Sciences, 2013

\title{
Numerical analysis of the discharge coefficient with disturbers for flowmetring accuracy
}

\author{
Boualem Laribi $^{1, \mathrm{a}}$, Abdelaziz Aït Amrane ${ }^{1}$ and Abdelkader Youcefi ${ }^{2}$ \\ ${ }^{1}$ FIMA Laboratory, University of Khemis Miliana, Route de Theniet El Had, Algeria \\ ${ }^{2}$ Mechanical department, University of Sciences and Technology Oran, Bir El Djir, Algeria
}

\begin{abstract}
The present work concerns a numerical investigation of the effect of orifice meter diameters on the discharge coefficient for flow measurement purpose. The flow is subject to two disturbers namely a $90^{\circ}$ double bend in perpendicular planes and a $50 \%$ closed valve. The turbulent flow is examined in conduit with an inner diameter of $D=100 \mathrm{~mm}$. The diameter of orifice meters are respectively $d=40,50$, 60,70 and $75 \mathrm{~mm}$ which done for $\beta$ ratio $\mathrm{d} / \mathrm{D}$ respectively the values of $0.4,0.5,0.6,0.7$ and 0.75 . The orifice meters are located in conduit at different stations downstream the disturbers. The flow is examined with air at Reynolds number $\mathrm{Re}=2.5 \times 10^{5}$. The software used for this simulation is CFD code Fluent with k- $\varepsilon$ like turbulence model. As a conclusion, the analysis of numerical results shows that when the diameter of the orifice meter increases the shifts deviation in the discharge coefficient increases this causes a great error in flow measurement. Contrary, when the diameter of the orifice meter decreases the shifts deviation in the discharge coefficient decreases and the errors in flow measurement is reduced. These results are the same with the two disturbers used separately in conduit.
\end{abstract}

\section{Introduction}

Orifice meters have been used for flow measurement for many years for process and fiscal proposes. The ability to accurately measure the flow rate of gas in a conduit is of major concern and vital importance where large volumes are handled. In Algeria, the quality of gas measurement receipt and major delivery points distributed through $13000 \mathrm{~km}$ on pipeline is very important. Errors in flow measurement can have large cost and efficiency implications in such a case.

The majority of the orifice meters must be calibrated. This is done in fully developed pipe flow, axisymmetric pipe that is free from swirl and pulsation. Standards such as ISO5167 (2003) define a satisfactory flow. While high accuracy about $0.5 \%$ flow rate measurement is required, disturbances in the flow caused by valves, bends, and other component introduce errors of more than $3 \%$.

Given that most industrial installations include disturbers like bends, valves, expanders and reducers, which are sources of swirl, asymmetries and turbulence distortions, insuring that fully developed flow in terms of mean flow and turbulence structure approach the meter is difficult to achieve in practical situations.

For best accuracy, a flow meter needs to be presented with an axisymmetric, fully developed velocity profile with zero swirls. Either very long lengths of straight pipe work upstream of the flow meter must be provided (recommended by ISO 5167, 2003) and these may need to be of the order of 80 to 100 pipe diameters, which will give a higher installation cost and greater space requirement. Research work by Gallagher P.E. and Saunders M.P. (2001), Laribi B. and al (2003), Sharipov F. (2004), Hongjian Z. and al (2006), Rick Rans (2008), Darin L. and Bowles E. B. (2008), Yehia A. and al (2009), Ahmadi A. (2009), Laribi B. and al (2010), Blaine D. (2010), have reported a number of experimental and computational studies of installation effects on orifice meter performances.

Our paper examines the effect of the orifice meter on the shift deviation of the discharge coefficient for best metrological performances basing on the pressure drop across the orifice in non-standard conditions. The investigation is conducted to show the effect of the two disturbers namely a $90^{\circ}$ double bends in perpendicular planes and a $50 \%$ closed valve on the deviation of the discharge coefficient.

\section{Turbulence models}

The general equation used in CFD code is given by Eq. 1 as bellow: 


$$
\frac{\partial}{\partial \boldsymbol{t}}(\rho \phi)+\nabla \boldsymbol{U} \phi=\nabla\left(\Gamma_{\phi} \operatorname{grad} \phi\right)+\boldsymbol{S}_{\phi} .
$$

Where:

$\phi$ a general variable which can be velocity $\mathrm{U}$ $\left(\mathrm{m} . \mathrm{s}^{-1}\right)$, turbulence kinetic energy $\mathrm{k}\left(\mathrm{kg} \cdot \mathrm{m}^{-2} \cdot \mathrm{s}^{-2}\right)$ or the dissipation rate $\varepsilon\left(\mathrm{m}^{-2} \cdot \mathrm{s}^{-3}\right)$. $\rho$ is the density of fluid $\left(\mathrm{kg} \cdot \mathrm{m}^{-3}\right)$. $\Gamma_{\phi}$ is the diffusion coefficient of the variable $\phi$. $\mathbf{S}_{\phi}$ is the source term of the variable $\phi$.

The turbulence model used for this simulation is k- $\varepsilon$ model. It is the simplest and complete model known as two equations. This model assumes that the turbulent regime is fully established throughout the area and that the effects of molecular viscosity are negligible compared to the turbulent viscosity (away from walls). It is based on the Boussinesq hypothesis. It is a semi-empirical model. Two transport equations are used, one for the turbulence kinetic energy $\mathrm{k}$ and the other for its dissipation rate $\varepsilon$. The reader can consult the literature Fluent (2006) for thorough study.

\section{Experimental facility for the simulation}

\subsection{Air Flow Rig}

The basic experimental facility is presented in Fig. 1. It consists of a long conduit pipe with $100 \mathrm{~mm}$ inner diameter. The air enters the pipe then flows through a straight pipe of 10D length, which is followed by disturbers. The $90^{\circ}$ double bend in perpendicular planes and $50 \%$ closed valve were used separately. The orifice meter diameters used in this simulation are respectively $\mathrm{d}=40,50,60,70$ and $75 \mathrm{~mm}$ diameters which done for $\beta$ ratio $\mathrm{d} / \mathrm{D}$ respectively the values of $0.4,0.5,0.6,0.7$ and 0.75 . The first orifice meter is installed at 97D downstream of the flow disturber, where the flow is fully developed. Stations used for the second orifice meters are respectively $6 \mathrm{D}, 7 \mathrm{D}, 9 \mathrm{D}, 10 \mathrm{D}, 12 \mathrm{D}, 13.5 \mathrm{D}, 17.5 \mathrm{D}, 20 \mathrm{D}$, 25D, 30D, 35D downstream the disturber.

The two orifice meters have standard geometry. A length of $10 \mathrm{D}$ is provided downstream the entrance of flow and downstream the orifice meter installed at station 91D for natural flow development. The Reynolds number of the turbulent flow is $2.5 \times 10^{5}$.

\subsection{Variation of the discharge coefficient}

For testing the effect of disturbers on the discharge coefficients of the orifice meters, the shift deviation for the discharge coefficient $\Delta \mathrm{Cd}(\%)$ is calculated by using the difference pressure $\Delta \mathrm{P}$ obtained by the simulation at different locations of the orifice meter in the pipe and $\Delta$ Po at the same time at station $\mathrm{z} / \mathrm{D}=97$ were the flow is fully developed. Eq. 2 shows the calculus formula:

$$
\Delta \mathrm{Cd}(\%)=\sqrt{\frac{\Delta \mathrm{Po}}{\Delta \mathrm{P}}}-1
$$

The difference pressure is calculated according to the standard ISO 5167 at D upstream and D/2 downstream the orifice meter. This formula was applied for the five orifice plates with the two disturbers.

\section{Results and discussion}

\subsection{Discharge coefficient errors with $50 \%$ closed valve on line}

In this case, experiments were conducted to determine the relative change in the orifice meter discharge coefficient when subjected to non-standard approaching flow conditions as the $50 \%$ closed valve. The test sections were $6 \mathrm{D}, 7 \mathrm{D}, 9 \mathrm{D}, 10 \mathrm{D}, 12 \mathrm{D}, 13.5 \mathrm{D}, 17.5 \mathrm{D}, 20 \mathrm{D}, 25 \mathrm{D}$, $30 \mathrm{D}, 35 \mathrm{D}$ downstream the valve. The effect of valve on the orifice meter with the five orifice meters with respectively, $\beta=0.40,0.50,0.60, \quad 0.70$ and 0.75 at Reynolds number of $2.5 \times 10^{5}$ is shown in Fig. 2. The principal remark shown in this figure is that when $\beta$ increases, $\Delta \mathrm{Cd}(\%)$ increases. This situation is the same for the five orifice meters used in this numerical study.

Indeed, we register at station $\mathrm{z} / \mathrm{D}=6.5$ a value close to zero for $\Delta \mathrm{Cd}(\%)$ with $\beta=0.4$. This value increases to reach $8 \%$ for $\beta=0.75$. We have to remember that the Standard ISO 5167 recommend a maximum value for $\Delta \mathrm{Cd}(\%)$ of $0.5 \%$. Our results are in good agreement with the standard for station $\mathrm{z} / \mathrm{D}=17.5$ and more. This result let's suppose that if we would like to get a good flow measurement, the orifice meter must be placed at station $z / D=17.5$ or more downstream the valve.

Figure 1. Conduit

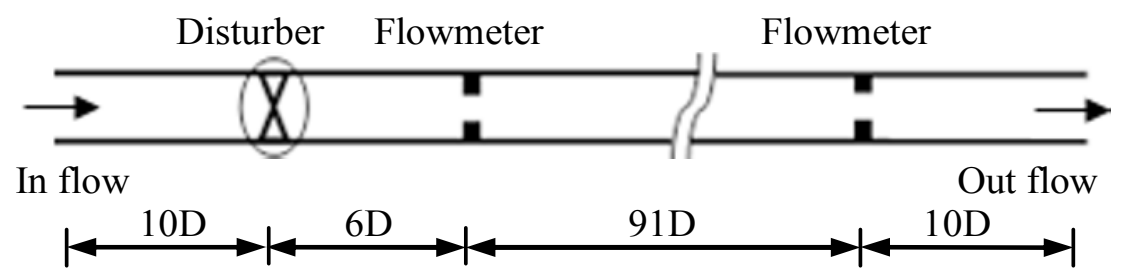


Figure 2. Discharge coefficient errors, valve $50 \%$ closed
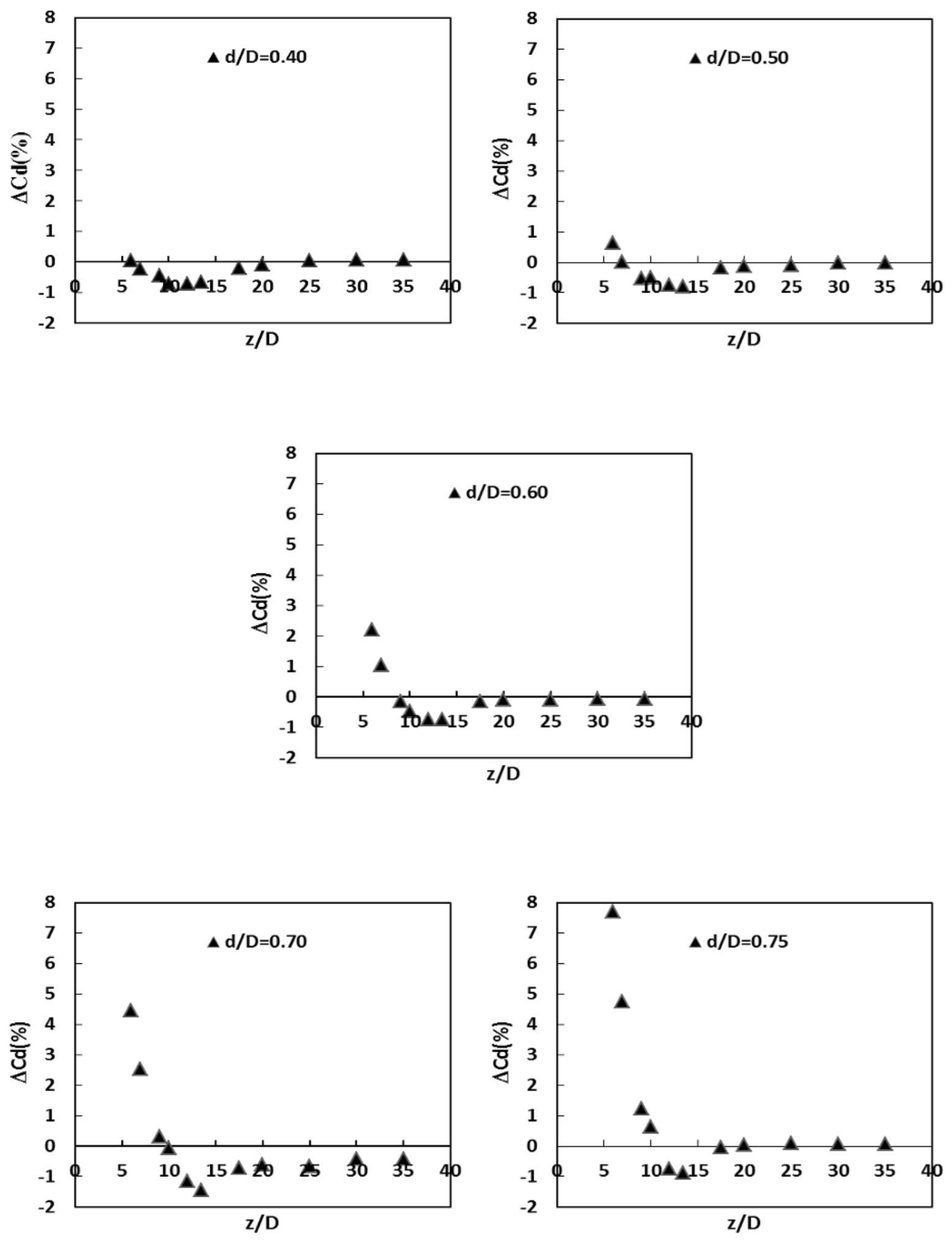
Figure 3. Discharge coefficient errors with double bend
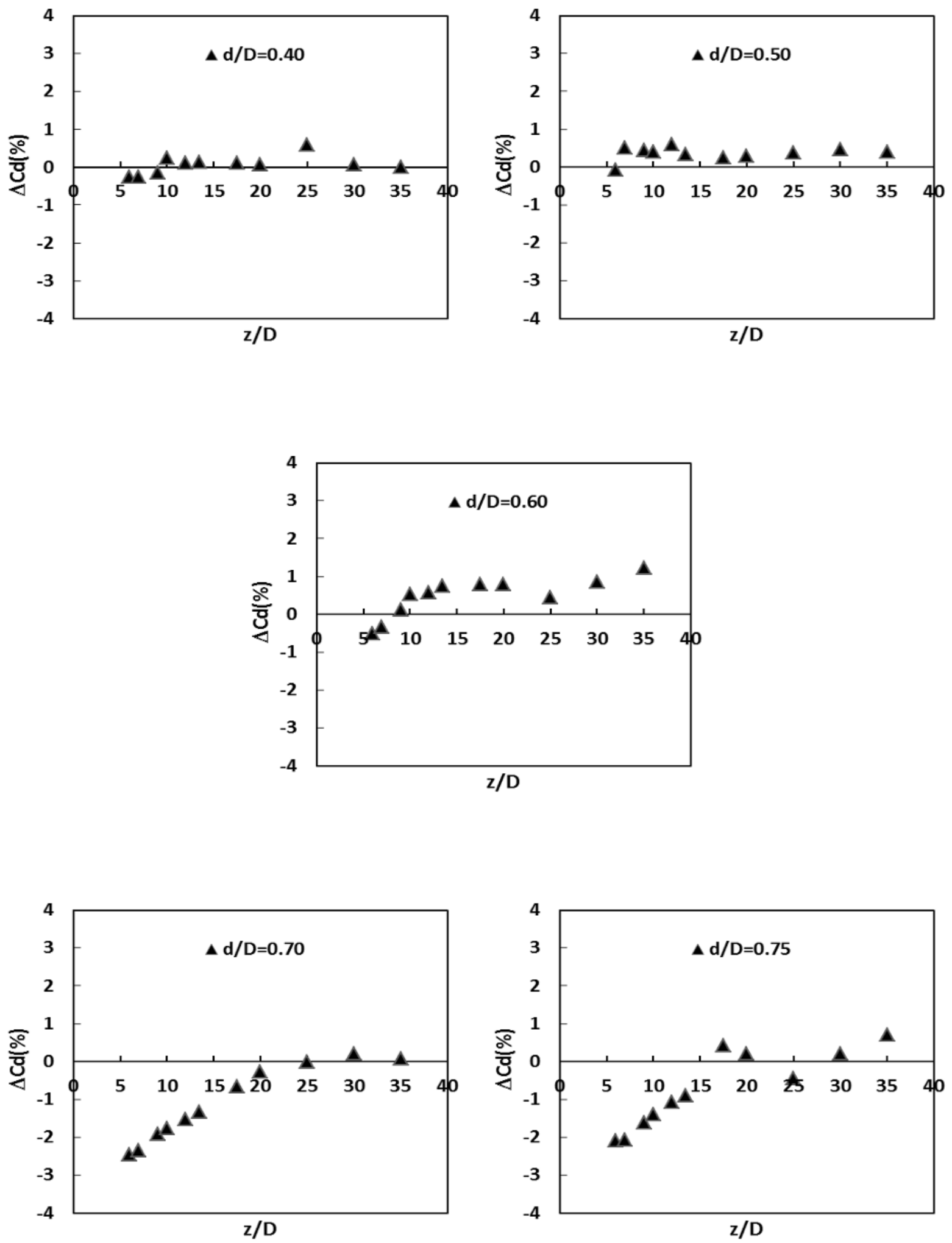


\subsection{Discharge coefficient errors with double bend on line}

In this case, experiments were conducted to determine the relative change in the orifice meter discharge coefficient when subjected to non-standard approaching flow conditions as the $90^{\circ}$ double bend in perpendicular planes. The test sections were 6D, 7D, 9D, 10D, 12D, 13.5D, 17.5D, 20D, 25D, 30D, 35D downstream the double bend. The effect of this disturbers on the orifice meter with the five orifice meters with respectively, $\beta=0.40,0.50,0.60,0.70$ and 0.75 with a Reynolds number of $2.5 \times 10^{5}$ is shown in Fig.3. The principal remark shown in this figure is the same which obtained with the valve. Indeed, when $\beta$ increases, $\Delta \mathrm{Cd}(\%)$ increases. This situation is the same for the five orifice meters used in this numerical study. We register at station $\mathrm{z} / \mathrm{D}=6.5$ a value close to $0.3 \%$ for $\Delta \mathrm{Cd}(\%)$ with $\beta=0.4$.

This value increases to reach $2.7 \%$ for $\beta=0.75$. Our results are in good agreement with the standard for station $\mathrm{z} / \mathrm{D}=17.5$ and more. This result is the same of results obtained for the valve.

\section{Conclusion}

The present numerical investigation examines the effect of upstream conditions on orifice meters otherwise on the discharge coefficient $\mathrm{Cd}$. The flow is disturbed by a $50 \%$ closed valve and a $90^{\circ}$ double bend in perpendicular planes used separately. The discharge coefficient were measured with five different orifice meters with $\beta=0.4$, $0.5,0.6,0.70$ and 0.75 at Reynolds number Rey $=2.5 \times 10^{5}$.

The principal result shows that when $\beta$ increases the shift deviation on the discharge coefficient $\Delta \mathrm{Cd}(\%)$ increases. This result is the same with the two disturbers. Indeed if we would like to get a good flow measurement, the flow meter must be located at distance $\mathrm{z}=17.5 \mathrm{D}$ downstream the disturber or more. In this situation, a good agreement is obtained with the standards ISO 5167.

We also concluded that the valve $50 \%$ closed could be considered for further experimental investigations than the $90^{\circ}$ double bend in perpendicular planes which gave minimum errors on the discharge coefficient contrary to the valve.

At last, the CFD shows their efficiency to predict the flow behaviour in different situations and let us to plain our experimental study in optimal conditions in order to validate the numerical investigations.

\section{Acknowledgements}

The authors acknowledge the High Ministry of Education and Scientific Research of Algeria for supporting financially this project.

\section{References}

1. A. Ahmadi, J. Fluids Engineering, 131, (2009)

2. D. Blaine, American School of Gas Measurement Technology, (2010)

3. L. Darin. and al, Pipe-line \& Gas Journal, 5962 (2008)

4. Fluent v 6.3, user's guide, (2006)

5. P.E. Gallagher, M.P Ssaunders. " $A G A 3, G F C$ qualifications, savant measurement corporation USA", (2001)

6. Z. Hongjian and al, J. Flow measurement and instrumentation, (2006)

7. ISO 5167, (2003)

8. B. Laribi, and al, The Eur J Mechanical and Environmental Engineering 48, (2003)

9. B. Laribi and al, "2010 ASME Fluids Engineering Division Summer Meeting and 8th Int Conf on Nanochannels, Microchannels and Minichannels", Montreal, Canada. (2010)

10. R. Rans, " $7^{\text {th }}$ South East Asia Hydrocarbon Flow Measurement Workshop”, (2008)

11. F. Sharipov, J. of Fluids Mechanics 518, 35-60 (2004)

12. Yehia and al, "Engineering applications of computational fluid mechanics” 3, 562-572 (2009) 